\title{
Continuing Education of Nurses in Patient Handovers: Development and Evaluation of a Digitally Enabled Problem-Based Learning Course
}

\author{
Nicole EGBERT ${ }^{\mathrm{a}, 1}$, Birgit BABITSCH ${ }^{\mathrm{b}}$ and Ursula HÜBNER ${ }^{\mathrm{a}}$ \\ ${ }^{a}$ Health Informatics Research Group, Osnabrück University AS, Germany \\ ${ }^{\mathrm{b}}$ New Public Health, Osnabrück University, Germany
}

\begin{abstract}
Communication deficits belong to the most frequent errors in patient handovers calling upon specialized training approaches to be implemented. This study aims to harness problem-based learning (PBL) methods in handover education and evaluated the learning process. A digitally enabled PBL course was developed and implemented at Klinikum Osnabrück from which eight nurses participated in the course. They agreed on the stimulating effect of the setting regarding selfdirected learning and on the potential to translate the new knowledge and skills into the daily clinical practice. In conclusion, the findings are promising that a digitally enabled PBL course is a suitable learning format for handover education.
\end{abstract}

Keywords. Education, nursing, handover, problem-based learning, online course

\section{Introduction}

Patient handovers and handoffs require a timely and proper transmission of nursing and medical information from the out-going to the incoming shift. Without such information transfer, patient safety is jeopardized [1]. Communication deficits belong to the most frequent errors that account to up to $80 \%$ of the critical incidents [2,3]. While it is known that handover trainings [4] can mitigate this situation, there is still a lack of appropriate opportunities during undergraduate, postgraduate and continuing education [5]. Students benefit from learning handovers that includes active elements such as role playing, simulation [5], real-world scenarios [6] or case-based learning [7].

One of the most well-known pedagogical methods for activating the learners is problem-based learning (PBL). Employing realistic case descriptions, so called case vignettes, it is a method that highlights the access to acquiring practically relevant knowledge and skills [8]. In the ideal case, PBL should enable the learners to take over the responsibility for the learning process [9]. PBL has been augmented towards its application in electronic learning environments in the last decade [10].

Despite its activating character, the realistic scenarios it relates to and its dedicated focus on working in teams, PBL has not been applied for teaching handovers or hand-

\footnotetext{
${ }^{1}$ Corresponding Author, Nicole Egbert, Health Informatics Research Group, Osnabrück University of Applied Sciences, Albrechtstr. 30, 49076 Osnabrück, Germany; E-mail: n.egbert@hs-osnabrueck.de.
} 
offs so far. It therefore seems worthwhile to harness PBL in handover trainings in particular for continuing education and evaluate the learning process. As training adults often is supported by digital elements or is entirely performed online, digitally enabled PBL should be the method of choice to be tested. The aim of this study, therefore, was to describe the development and the evaluation of a handover course in continuing education using the digitally enabled PBL approach. The research questions are as follows: 1) To what extent was this course suitable to foster active learning? 2) Did the course elements refer to clinically relevant situations and to what extent did the course help to transfer the new knowledge into practice?

\section{Methods}

The course development including the one of the case vignette was based on prior own work that helped to identify communication errors as the primary critical safety issue in patient handover via a CIRS analysis [11]. The case vignette thus reflected a face-to-face patient handover between two nursing shifts with typical communication deficits.

The overall learning objective of the course was that, upon completion of the course, participants will have knowledge and communication skills that will enable them to ensure information continuity in patient handovers. Hereby, the aim is to improve patient safety proactively identifying and avoiding potential harm. The course was structured into three phases following the 7 steps of PBL (Fig. 1).
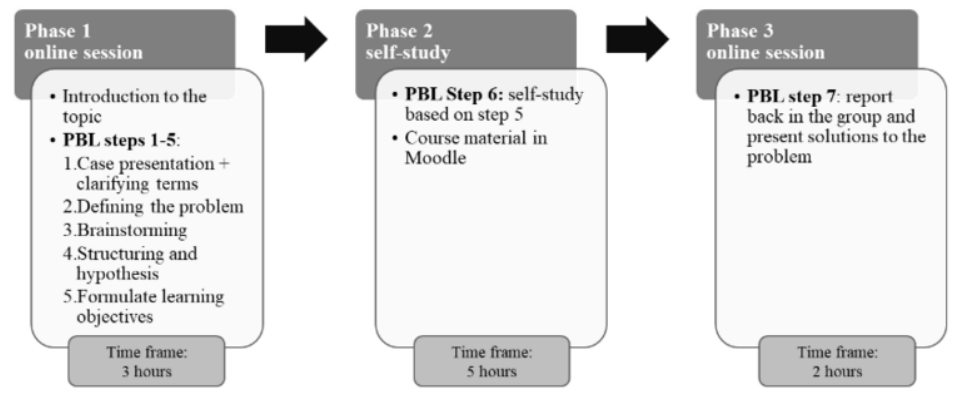

Figure 1. Course timeline

All in all, it took 10 hours and included two synchronous online sessions together with two tutors (phase 1 and 3 ) and one asynchronous self-study phase (phase 2). The online sessions were realized via Zoom and were recorded, the course content was published via the learning management platform Moodle. During the first online phase the students had to work on the definition of the problems in the case vignette, the collection and systematic compilation of ideas and solutions, and the identification of the learning objectives. The results of the group were documented on the digital pin wall Padlet ${ }^{\circledR}$. The course material for the self-study phase (phase 2) consisted of texts, graphics, videos, tests and quizzes as well as assignments to reflect the topics patient safety, high reliability organisations, patient handovers, communication, structuring the handover information and electronic systems to support handovers. During this phase, students worked on their own. The second online session was used to report back to the group and present solutions to the problems.

The course was held at Klinikum Osnabrück, a 768 beds municipal hospital, involving 8 registered nurses in leading positions ( 6 females, 2 males, one person was 
younger than 30 years, three between 30 and 44 years and three persons older than 44). It took place between August 26th and September 16th, 2020 allowing three weeks for the self-study phase. The learning process was evaluated in a pre-post design, whereby the pre-questionnaire addressed amongst others previous experience, and prior knowledge. The post-questionnaire consisted of questions concerning the learning experience in the PBL course and the translation of the knowledge into practice. Some of the questions were identical to allow for a before-after comparison.

\section{Results}

The analysis of the pre-questionnaire indicated that there was a wide variety of prior experience regarding eLearning, case vignettes and PBL from "not at all" to "a large extent". The course participants had either none or experience "to a medium extent" with learning management platforms. The analysis of the post-questionnaire revealed that the participants agreed either "rather" or "fully" to statements concerning the relevance of the case vignette, the stimulating effect of the learning setting regarding self-study and obtaining multiple perspectives (Fig. 2).

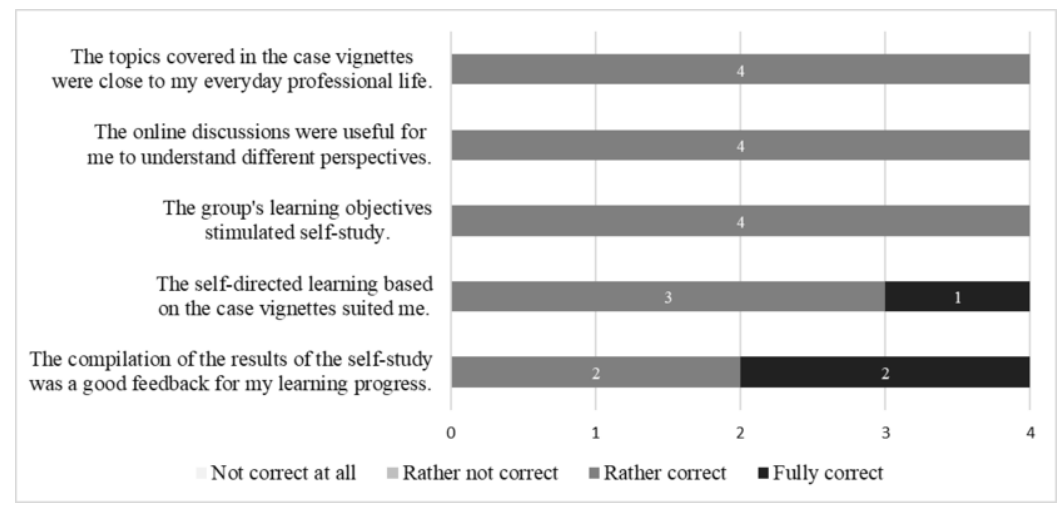

Figure 2. Evaluation of the problem-based learning setting (post-questionnaire) $(n=4)$

Alike, the participants concurred with the statements about the translation of the new knowledge gained in this course into the daily clinical practice (Fig. 3). Due to organizational problems not all course participants submitted the questionnaires. However, all participants gave feedback stating that the use of the learning platform was easy and helpful as was expressed by one of the persons "The course structure was very intuitive. It was very useful for me to watch the recordings of the online sessions." Also, all participants agreed that taking this course was compatible with their work.

\section{Discussion}

The present study demonstrated the feasibility and usefulness of a digitally enabled PBL course in continuing education. Despite the heterogeneity of the prior experience in eLearning, it was generally agreed that using the electronic learning environment was easy and provided added value. In accordance with the literature [8], the PBL course activated the students to engage in self-directed learning. Due to the perceived practical 
relevance of the case vignette, the students expected the new knowledge and skills to be sustainable and transferable into practice.

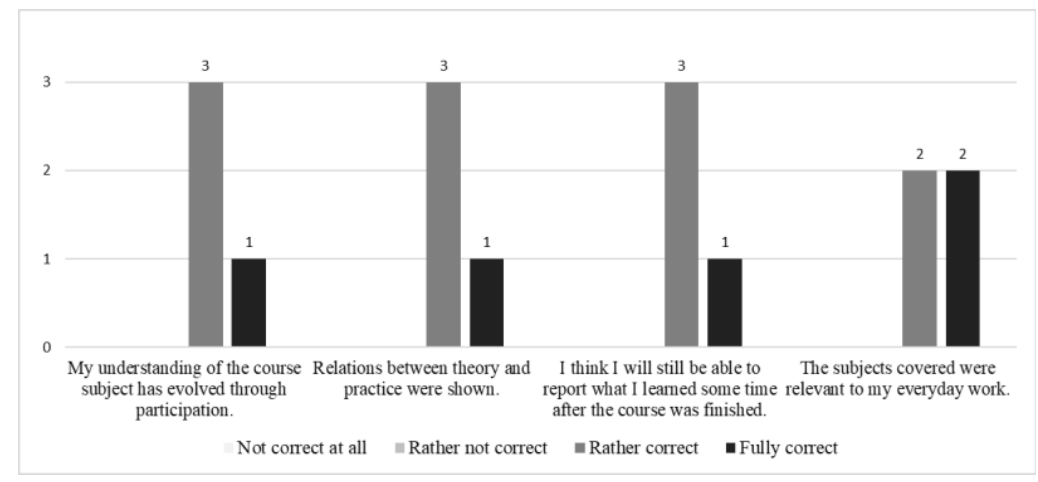

Figure 3. Evaluation of translation of knowledge into practice (post-questionnaire) $(n=4)$

The interpretation of the findings suffers from the fact that not all participants took part in the post-questionnaire. However, the final feedback including all participants yielded a positive impression. In conclusion, the findings are promising that a digitally enabled PBL course is a suitable learning format in continuing education and for training handovers particularly. Additional implementations of the course would be useful for further improvement and development of the course.

\section{Acknowledgement}

This study was supported by a grant from the VolkswagenStiftung Hannover, Germany (grant no. ZN3123). We wish to thank Klinikum Osnabrück for their interest and support.

\section{References}

[1] Australian Council for Safety and Quality in Health Care. Clinical Handover and Patient Safety Literature Review Report. March 2005.

[2] Flemming D, Hübner U. How to improve change of shift handovers and collaborative grounding and what role does the electronic patient record system play? Results of a systematic literature review. Int $\mathbf{J}$ Med Inform. 2013 Jul;82(7):580-592.

[3] Galatzan BJ, Carrington JM. Exploring the State of the Science of the Nursing Hand-off Communication. Comput Inform Nurs. 2018 Oct;36(10):484-493.

[4] Halm MA. Nursing handoffs: ensuring safe passage for patients. Am J Crit Care. 2013;22(2):158-162.

[5] Gordon M, Hill E, Stojan JN, Daniel M. Educational Interventions to Improve Handover in Health Care: An Updated Systematic Review. Acad Med. 2018 Aug;93(8):1234-1244.

[6] Riesenberg LA, Leitzsch J, Cunningham JM. Nursing Handoffs: A Systematic Review of the Literature. Am J Nurs. 2010 Apr;110(4):24-34.

[7] Klaber RE, Macdougall CF. Maximising learning opportunities in handover. Arch Dis Child Educ Pract Ed. 2009 Aug;94(4):118-122.

[8] Bligh J. Problem-based learning in medicine: an introduction. Postgrad Med J. 1995;71:323-326.

[9] de Grave W, Moust J, Hommes J. The role of the tutor in a problem based learning curriculum. Maastricht: Maastricht University; 2003.

[10] Saqr M, Nouri J, Vartiainen H, Malmberg J. What makes an online problem-based group successful? A learning analytics study using social network analysis. BMC Med Educ. 2020 Mar 18;20(1):80.

[11] Egbert N, Babitsch B, Hübner U. Learning from CIRS to optimise patient safety in handovers. GMS Med Inform Biom Epidemiol. 2020;16(3):Doc10. DOI: 10.3205/mibe000213. 